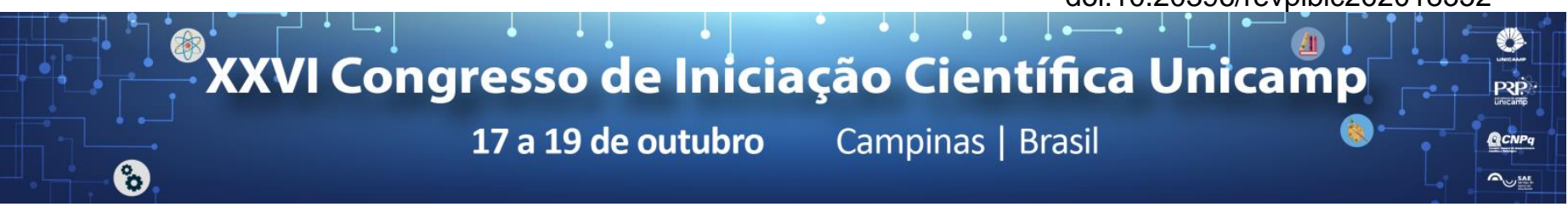

\title{
Análise morfométrica do músculo masseter de ratos Wistar
}

\section{Diego Alves da Silva*, Alexandre Rodrigues Freire, Ana Cláudia Rossi, Felippe Bevilacqua Prado.}

\section{Resumo \\ O objetivo deste estudo foi descrever a morfologia do músculo masseter em rato Wistar.}

\section{Palavras-chave:}

morfologia, anatomia, músculos da mastigação.

\section{Introdução}

O masseter é o músculo dominante na função de elevar a mandíbula, formando entre $60 \%$ e $80 \%$ da musculatura mastigatória ${ }^{1}$, e é dividido em três camadas em roedores: o masseter superficial, masseter profundo e zigomaticomandibular. As alterações e tensões ósseas geradas no crânio pela musculatura da mastigação podem ser estudadas através da análise de elementos finitos, na qual a mastigação pode ser simulada em diversas condições. Para que os resultados das simulações sejam mais fiéis aos movimentos realizados pelos animais, é necessário que o modelo utilizado nas simulações seja representativo da morfologia óssea e muscular da área de estudo. Porém não há atualmente na literatura informações suficientes sobre a musculatura da espécie estudada. $O$ objetivo do trabalho foi descrever a morfologia do músculo masseter em ratos da espécie Wistar

\section{Resultados e Discussão}

Foram utilizados 7 ratos machos (Rattus norvegicus albinus), linhagem Wistar, com 4 meses de idade (400g), provenientes do CEMIB-UNICAMP. Foram mantidos em gaiolas coletivas (quatro animais/caixa), com temperatura em $22 \pm 2^{\circ} \mathrm{C}$, ciclo de luz controlado (12/12 h) e acesso livre à água e ração. Após eutanásia, as cabeças dos animais foram dissecadas com instrumentais apropriados. Ao alcançar a musculatura da mastigação em cada espécime, o músculo masseter de cada lado foi isolado dos demais tecidos para realização de um estudo descritivo de caráter qualitativo. $\mathrm{Na}$ dissecção, observou-se que o músculo masseter superficial apresenta ao lado de sua folha tendinosa, que cobre cerca de um terço da superfície lateral, fibras que correm obliquamente da parte anterior do crânio para a porção posterior da mandíbula. A origem tendinosa dos masseteres superficiais é um pequeno processo no osso maxilar do crânio, imediatamente ao centro do forame infraorbital. As fibras que se originam da folha tendinosa correm posteriormente, seguindo o caminho oblíquo do tendão e do músculo, e se insere no corpo da mandíbula em ambos os lados e nas superfícies medianas.

\section{Conclusões}

Os resultados deste estudo permitiram compreender a relação funcional entre a morfologia da mandíbula e a musculatura da mastigação em ratos Wistar.

\section{Agradecimentos}

Os autores são gratos ao apoio financeiro recebido pelo Conselho Nacional de Desenvolvimento Científico e Tecnológico (PIBIC-EM-CNPq).

1 Turnbull, W.D. Fieldiana (Geol). 1970; v. 18, p. 147-356. 